\title{
KAJIAN EKOSISTEM TERUMBU KARANG UNTUK PENGEMBANGAN EKOWISATA BAHARI PULAU TIKUS BENGKULU
}

\author{
Oleh \\ Maria Pustikawati ${ }^{*}$, Yar Johan dan Dede Hartono \\ Program Studi IImu Kelautan Fakultas Pertanian Universitas Bengkulu, Bengkulu \\ *Email: puwamaria16@gmail.com \\ Received March 2016, Accepted April 2016
}

\begin{abstract}
ABSTRAK
Pulau Tikus merupakan pulau kecil yang terletak di sebelah Barat Kota Bengulu. Dengan jarak sekitar $10 \mathrm{~km}$ dari pusat kota. Pulau Tikus memiliki potensi ekowisata bahari terumbu karang dengan perairan yang jernih dan bersih sehingga keindahannya menjadi daya tarik tersendiri bagi pengunjung. Terumbu karang yang ada di Pulau Tikus bisa dimanfaatkan sebagai objek ekowisata yaitu ekowisata bahari kategori diving dan snorkeling. Tujuan dari penelitian ini adalah mengidentifikasi potensi ekosistem terumbu karang di Pulau Tikus dan menganalisis kesesuaian kawasan ekowisata bahari kategori diving dan snorkeling. Kualitas air terdiri atas kecerahan, suhu, kecepatan arus, dan kedalaman. Analisis kondisi penutupan karang menggunakan Line intecept transec, analisis ikan karang menggunakan Underwater Visual Census dan analisis kesesuaian menggunkan indeks kesesuaian kawasan. Rata-rata tutupan ekosistem terumbu karang yang ada di Pulau Tikus yaitu 37,59\% masuk kategori (sedang). Rata-rata kesesuaian ekowisata bahari kategori diving yaitu 60,4\% masuk dalam kategori S2 (sesuai) dan rata-rata kesesuaian ekowisata bahari kategori Snorkeling yaitu 46,33\% masuk dalam kategori S3 (sesuai bersyarat).
\end{abstract}

Kata kunci : Terumbu karang, ekowisata, pulau tikus, bengkulu.

\begin{abstract}
ABSTRAK
Tikus Island is a small island that located beside went of Bengkulu city. Aproximately $10 \mathrm{~km}$ from bengkulu city. Tikus Island have the ecotourism potency of coral reef with the clear and clean water, so the beauty of the island become the secluded for the visitor. Then purpose of this reseach is to identify the potention of coral reef ecosystem in Tikus Island and analyzed the ecotourism maritim area it is comfortable or not as the diving and snorkeling area. The quality of water consist of coral closing condition with Line Intecept Transeck, the analized of coral fist with Underwater Visual Census and also the analyzed of adaptation with adaptation Index Area Ecotourism. Average the closing coral reef ecosystem in tikus island is $37,5 \%$ in medium category. The average of ecotourism adaptation in diving Category is 60,4\%, include in S2 category and the average of maritim ecotourism adaptation in snorkeling category is $46,3 \%$ the include into S3 category ecording to conditiony.
\end{abstract}

key Word : Coral reef, ecotourism, tikus island, bengkulu. 


\section{PENDAHULUAN}

Provinsi Bengkulu terletak di pantai Barat Sumatera pada garis lintang $2^{0} 16^{\prime} 3^{0} 31$ LS dan garis bujur $101^{0} 1^{\prime} 103^{\circ} 41^{\prime}$ BT. Terletak di sebelah Barat pegunungan Bukit Barisan dan memanjang dari perbatasan Provinsi Sumatera Barat sampai keperbatasan Provinsi Lampung sepanjang kurang lebih $567 \mathrm{~km}$. Kota Bengkulu dengan luas wilayah $151,70 \mathrm{~km}^{2}$, terletak di pantai Barat Pulau Sumatera dengan pantai sekitar $525 \mathrm{~km}$ (Bappeda, 2013).

Pulau Tikus sebagai satu-satunya pulau yang ada di Kota Bengkulu. Dikelilingi terumbu karang yang sangat luas sehingga mampu melindungi pulau dari abrasi akibat gelombang yang besar. Namun keberadaan terumbu karang di Pulau Tikus sudah lama mengalami degradasi karena adanya pengrusakan karang oleh manusia. Rusaknya terumbu karang telah memberikan dampak negatif terhadap Pulau Tikus, hal ini terlihat dengan semakin berkurangnya luas Pulau Tikus karena mengalami abrasi yang berlangsung makin cepat dari tahun ke tahun. Erosi pantai merupakan salah satu masalah serius perubahan garis pantai. Selain proses alami, seperti angin, arus dan gelombang, aktivitas manusia menjadi penyebab terjadinya erosi pantai (Bakhtiar, 2013).

Pulau Tikus merupakan pulau kecil yang terletak di sebelah Barat Kota Bengulu. Dengan jarak sekitar $10 \mathrm{~km}$ dari pusat kota. Pulau Tikus memiliki potensi ekowisata bahari terumbu karang dengan perairan yang jernih dan bersih sehingga keindahannya menjadi daya tarik tersendiri bagi pengunjung.

Salah satunya ekosistem perairan tropis yaitu ekosistem terumbu karang. Terumbu karang merupakan ekosistem bahari yang banyak menarik perhatian karena merupakan daerah alamiah yang dibandingkan dengan ekosistem lainnya. Terumbu karang merupakan ekosistem paling indah dalam hal warna dan bentuk serta desainnya, sangat kaya akan keanekaragaman jenis biota yang hidup di dalamnya (Nybakken, 1992).

Ekowisata bahari merupakan bentuk pengelolaan sumber daya pesisir dan laut yang dikembangkan dengan pendekatan konservasi (Ketjulan, 2011).

Ekowisata bahari tidak mengedepankan faktor pertumbuhan ekonomi, melainkan menjaga keseimbangan antara kegiatan pemanfaatan dan kelestarian sumber daya (Yulianda, 2007) Untuk menjamin keberlangsungan dan kegiatan pariwisata bahari, maka diperlukan perlindungan terhadap ekosistem terumbu karang dan membentuk suatu blok perlindungan (Arifin dkk., 2002).

Terumbu karang yang ada di Pulau Tikus bisa dimanfaatkan sebagai objek ekowisata yaitu ekowisata bahari kategori diving dan snorkeling. Sehubungan masih sedikitnya penelitian tentang analisis kesesuaian kawasan ekowisata bahari kategori diving dan snorkeling di Pulau Tikus sehingga penulis tertarik untuk melakukan penelitian ini.

\section{METODE PENELITIAN}

\section{Tempat dan Waktu Penelitian}

Penelitian dilakukan di perairan Pulau Tikus. Waktu penelitian dari Bulan Oktober 2015- Januari 2016.

\section{Alat dan Bahan Penelitian}

Alat dan bahan pada saat penelitian dapat dilihat pada Tabel 2. 
Tabel 2.Alat dan Bahan Penelitian

\begin{tabular}{lll}
\hline No & Alat & Kegunaan \\
\hline 1. & Buku identifikasi karang & Panduan untuk mengidentifikasi Karang \\
2. & Camera under water & Untuk dokumentasi kegiatan di laut \\
3. & Meteran roll & $\begin{array}{l}\text { Untuk mengukur garis line transek } \\
\text { pengamatan }\end{array}$ \\
4. & Scuba diving & Alat bantu menyelam dalam pengambilan \\
& & sampel \\
5. & GPS & Untuk menentukan posisi lokasi penelitian \\
6. & Water checker & Untuk mengukur suhu \\
7. & Hand refraktometere & Mengukur salinitas \\
8. & Current metere & Mengukur kecepatan arus \\
10 & Secchi disk & Mengukur Kecerahan \\
11 & Scuba diving & Mengukur kedalaman \\
\hline
\end{tabular}

\section{Analisis Kualitas Air}

\section{Analisis Data}

Data parameter kualitas air yang diukur pada lokasi penelitian, diolah menjadi bentuk tabulasi data yang selanjutnya dianalisis dengan deskriptif kuantitatif. Analisa data yang digunakan dalam penelitian ini adalah persen tutupan komunitas karang (English et al., 1997), kelimpahan ikan karang (English et al., 1997), indeks kesesuaian ekowisata bahari (Yulianda, 2007).

\section{Analisis Tutupan Terumbu Karang}

Pengolahan data persentase penutupan karang dari metode Line Intercept Transeck (LIT) menggunakan Microsoft Office Excel 2007 Data persentase tutupan komunitas karang diperoleh berdasarkan metode Line Intercept Transect (LIT) dengan persamaan :

$$
\begin{array}{ll}
\text { Keterangan } & \mathrm{N}=\sum \frac{l i}{L} \times 100 \% \\
N & =\text { Persen penutupan karang } \\
L i & =\text { Panjang total lifeform ke-i } \\
L & =\text { Panjang transek } 50 \text { meter }
\end{array}
$$

\section{Analisis Ikan Karang}

Pengelompokkan ikan karang berdasarkan peranannya menurut Terangi (2014): 1) Ikan Target Ikan yang merupakan target untuk penangkapan atau lebih dikenal juga dengan ikan ekonomis penting atau ikan konsumsi seperti, Seranidae, Lutjanidae, Kyphosidae, Lthrinidae, Acanthuridae, Mulidae, Siganidae, Labridae (cehelinus, Himgymus, Choerodon) dan Haemulidae. 2) Ikan indikator Sebagai ikan penentu untuk terumbu karang karena ikan ini erat hubunganya dengan kesuburan terumbu karang yaitu ikan dari Famili Chaetodontidae (kepe-kepe). 3) Ikan lain ( Mayor Famili) Ikan ini umumnya dalam jumlah banyak dijadikan ikan hias air laut (pomacentridae, Caesoridae, Scaridae, Pomacanthidae, Apogonidae ). 
Analisis Kesesuaian Kawasan

Matriks kesesuaian untuk ekowisata bahari kategori diving dapat dilihat pada (Tabel 5) dan matriks kesesuaian untuk ekowisata bahari kategori snorkeling dapat dilihat pada (Tabel 6).

Tabel 5. Matriks kesesuaian lahan untuk ekowisata bahari kategori wisata diving

\begin{tabular}{|c|c|c|c|c|c|c|c|c|c|c|}
\hline \multirow{2}{*}{$\begin{array}{l}N \\
0\end{array}$} & \multirow[t]{2}{*}{ Parameter } & \multirow{2}{*}{$\begin{array}{c}\text { Bobo } \\
t\end{array}$} & \multicolumn{8}{|c|}{ Kategori dan Skor } \\
\hline & & & $\begin{array}{l}\text { Katego } \\
\text { ri } \\
\text { S1 }\end{array}$ & Skor & $\begin{array}{l}\text { Katego } \\
\text { ri } \\
\text { S2 }\end{array}$ & $\begin{array}{l}\text { Sko } \\
r\end{array}$ & $\begin{array}{l}\text { Kategori } \\
\text { S3 }\end{array}$ & Skor & $\begin{array}{l}\text { Katego } \\
\text { ri } \\
\mathrm{N}\end{array}$ & Skor \\
\hline 1. & $\begin{array}{l}\text { Kecerahan( } \\
\%)\end{array}$ & 5 & $>80$ & 3 & $>50-80$ & 2 & $20-<50$ & 1 & $<20$ & 0 \\
\hline 2. & $\begin{array}{l}\text { Tutupan } \\
\text { komunitas } \\
\text { karang (\%) }\end{array}$ & 5 & $>75$ & 3 & $>50-75$ & 2 & $25-50$ & 1 & $<25$ & 0 \\
\hline 3. & $\begin{array}{l}\text { Bentuk } \\
\text { pertumbuh } \\
\text { an } \\
\text { karang/Life } \\
\text { form }\end{array}$ & 3 & $>12$ & 3 & $>7-12$ & 2 & $4-7$ & 1 & $<4$ & 0 \\
\hline 4. & $\begin{array}{l}\text { Jenis ikan } \\
\text { karang } \\
\text { (spesies) }\end{array}$ & 3 & $>100$ & 3 & $\begin{array}{l}>50- \\
100\end{array}$ & 2 & $>20-50$ & 1 & $<20$ & 0 \\
\hline 5. & $\begin{array}{l}\text { Kedalaman } \\
\text { (m) }\end{array}$ & 1 & $6-15$ & 3 & $15-20$ & 2 & $>20-30$ & 1 & $>30$ & 0 \\
\hline 6. & $\operatorname{Arus}(\mathrm{cm} / \mathrm{dt})$ & 1 & $0-15$ & 3 & $>15-30$ & 2 & $>30-50$ & 1 & $>50$ & 0 \\
\hline
\end{tabular}

Sumber:Yulianda (2007). Keterangan : Nilai maksimum $=54$

Tabel 6. Matrik kesesuaian lahan untuk ekowisata bahari kategori wisata snorkeling

\begin{tabular}{|c|c|c|c|c|c|c|c|c|c|c|}
\hline \multirow{2}{*}{$\begin{array}{l}\mathrm{N} \\
\mathrm{O}\end{array}$} & \multirow{2}{*}{$\begin{array}{l}\text { Paramet } \\
\text { er }\end{array}$} & \multirow[t]{2}{*}{ Bobot } & \multicolumn{8}{|c|}{ Kategori dan Skor } \\
\hline & & & $\begin{array}{l}\text { Kategori } \\
\text { S1 }\end{array}$ & Skor & $\begin{array}{l}\text { Kategori } \\
\text { S2 }\end{array}$ & Skor & $\begin{array}{l}\text { Kategori } \\
\text { S3 }\end{array}$ & Skor & $\begin{array}{l}\text { Kategori } \\
\mathrm{N}\end{array}$ & Skor \\
\hline 1. & $\begin{array}{l}\text { Kecerahan( } \\
\%)\end{array}$ & 5 & 100 & 3 & $>80-100$ & 2 & $20-<80$ & 1 & $<20$ & 0 \\
\hline 2. & $\begin{array}{l}\text { Tutupan } \\
\text { komunitas } \\
\text { karang (\%) }\end{array}$ & 5 & $>75$ & 3 & $>50-75$ & 2 & $25-50$ & 1 & $<25$ & 0 \\
\hline 3. & $\begin{array}{l}\text { Bentuk } \\
\text { pertumbuh } \\
\text { an } \\
\text { karang/Life } \\
\text { form }\end{array}$ & , & $>12$ & 3 & $>7-12$ & 2 & $4-7$ & 1 & $<4$ & 0 \\
\hline 4. & $\begin{array}{l}\text { Jenis ikan } \\
\text { karang } \\
\text { (spesies) }\end{array}$ & 3 & $>50$ & 3 & $>30-50$ & 2 & $>10-<30$ & 1 & $<10$ & 0 \\
\hline 5. & $\begin{array}{l}\text { Kecepatan } \\
\text { arus } \\
\text { (cm/det) }\end{array}$ & 1 & $0-15$ & 3 & $>15-30$ & 2 & $>30-50$ & 1 & $>50$ & 0 \\
\hline 6. & $\begin{array}{l}\text { Kedalaman } \\
\text { dasar } \\
\text { perairan } \\
\text { (m) }\end{array}$ & 1 & $1-3$ & 3 & $>3-6$ & 2 & $>6-10$ & 1 & $>10,<1$ & 0 \\
\hline 7. & $\begin{array}{l}\text { Lebar } \\
\text { Hamparan } \\
\text { data karang } \\
\text { (m) }\end{array}$ & g & $>500$ & 3 & $>100-500$ & 2 & $20-100$ & 1 & $<20$ & 0 \\
\hline
\end{tabular}


Evaluasi terhadap parameter kesesuaian (lihat Tabel 5 dan Tabel 6) mencakup 4 kelas dengan kriteria: 1) S1 Nilai 75 - 100\% ( sangat sesuai). Suatu kawasan yang dikembangkan tidak mempunyai pembatas yang sesuai untuk menerapkan perlakuan yang diberikan atau hanya mempunyai pembatas yang tidak berarti atau tidak berpengaruh secara nyata terhadap penggunaannya dan tidak akan menaikkan atau tidak berpengaruh secara nyata terhadap penggunaannya dan tidak akan menaikkan masukan/tingkatan perlakuan yang diberikan. 2) S2 Nilai 50-75 (sesuai). Suatu kawasan memiliki pembataspembatas yang agak serius untuk mempertahankan tingkat perlakuan yang harus diterapkan. Pembatas ini akan meningkatkan masukan/tingkatan perlakuan yang diperlukan. 3) S3 Nilai 25-49\% (sesuai bersyarat). Suatu daerah mempunyai pembatas-pembatas yang serius untuk mempertahankan tingkat perlakuan yang harus diterapkan. Pembatas akan lebih meningkatkan masukan perlakuan yang diperlukan. 4) N Nilai $<25$ (tidak sesuai). Suatu daerah memiliki pembatas yang permanen, sehingga mencerminkan segala kemungkinan perlakuan pada daerah tersebut.

Indeks kesesuaian ekowisata bahari dihitung dengan rumus Yulianda (2007): $\mathrm{IKW}=\left(\sum \mathrm{Ni} / \mathrm{N} \max \right) \times 100 \%$

Keterangan $=$

IKW $=$ Indeks Kesesuaian Wisata

$\mathrm{Ni} \quad=$ Nilai Parameter Ke-i (Bobot $x$ Skor)

$\mathrm{N}$ maks $\quad=$ Nilai Maksimum dari suatu Kategori Wisata

Jumlah $\quad=$ Skor $\times$ Bobot

\section{HASIL DAN PEMBAHASAN}

Secara geografis Pulau Tikus terletak pada $102^{0}$ 9'30”- $102^{0} 10$ ' $57^{\prime}$ " BT dan $03^{\circ} 49^{\prime} 30^{\prime \prime}-03^{\circ} 51^{\prime} 0^{\prime \prime}$ LS, atau terletak di sebelah Barat Kota Bengkulu dan merupakan salah satu pulau yang terdekat di wilayah Kota Bengkulu.

\section{Analisis Indeks Kesesuaian Kawasan Kesesuaian Ekowisata Diving}

Hasil perhitungan parameter kesesuaian kawasan ekowisata bahari kategori diving (Tabel 9) dapat dilihat bahwa terdapat 3 kelas kesesuaian kawasan yaitu kategori S1 (sangat sesuai) S2 (sesuai), dan S3 (sesuai bersyarat).

Tabel 9. Hasil analisis indeks kesesuaian kawasan ekowisata bahari kategori diving

\begin{tabular}{cccc}
\hline Stasiun & IKW & Kategori & Keterangan \\
\hline Stasiun 1 & $44 \%$ & S3 & Sesuai Bersyarat \\
Stasiun 2 & $75 \%$ & S1 & Sangat Sesuai \\
Stasiun 3 & $50 \%$ & S2 & Sesuai \\
Stasiun 4 & $53 \%$ & S2 & Sesuai \\
Stasiun 7 & $80 \%$ & S1 & Sangat Sesuai \\
\hline
\end{tabular}

Berdasarkan hasil analisis indeks kesesuain kawasan ekowisata bahari kategori diving yang disajikan pada Tabel 9 menunjukkan bahwa terdapat 3 kategori kelas kesesuaian kawasan. Katergori S1 ( sangat sesuai) terdapat pada stasiun 1 dan 7. Kategori S2 ( sesuai) terdapat pada stasiun 3 dan 4. Kategori S3 (sesuai Bersyarat) terdapat pada stasiun 1. Kategori S1 (sangat sesuai) sama dengan penelitian yang ada di pulau lara yaitu bahwa pada stasiun 1 termasuk kategori S1 (sangat sesuai) untuk kegiatan wisata diving namun masih ada beberapa parameter yang memiliki nilai dibawah standar kesesuaian kawsan 
kategori S1 yaitu pada parameter jumlah lifeform dan jenis ikan karang. Kedua parameter ini masih bisa ditingkatkan kualitasnya dengan melakukan transplantasi terumbu karang yang dapat meningkatkan jumlah lifeform dan melakukan pelarangan penangkapan ikan karang dikawasan terumbu karang Pulau lara (Adi dkk., 2013). Kategori S2 yang merupakan kategori sesuai. Hal ini di sebabkan karena masih ada beberapa faktor parameter untuk kesesuaian wisata tersebut yang minim dan menjadi faktor pembatas bagi kesesuaian kawasan untuk di jadikan kawasan wisata (Adi dkk., 2013).

Kesesuaian Ekowisata Snorkeling

Kesesuaian kawasan kategori snorkeling dapat di lihat pada Tabel 10.

Tabel 10. Hasil analisis kesesuaian kawasan ekowisata bahari kategori Snorkeling

\begin{tabular}{lccc}
\hline \multicolumn{1}{c}{ Stasiun } & IKW & Kategori & Keterangan \\
\hline Stasiun 5 & $47 \%$ & S3 & Sesuai Bersyarat \\
Stasiun 6 & $45 \%$ & S3 & Sesuai Bersyarat \\
Stasiun 8 & $47 \%$ & S3 & Sesuai Bersyarat \\
\hline
\end{tabular}

Berdasarkan hasil analisis indeks kesesuaian kawasan ekowisata bahari kategori snorkeling yang disajikan pada Tabel 10 menunjukkan bahwa terdapat 1 kategori kelas kesesuaian kawasan yaitu kategori S3 (Sesuai Bersyarat). Hal ini di sebabkan karena pada stasiun ini persentase kecerahan, tutupan terumbu karang, bentuk pertumbuhan karang (Lifeform) dan jenis ikan karangnya rendah.

Ekowisata laut memberikan beragam jasa rekreasi bagi manusia. Kesejahteraan masyarakat diharapkan akan meningkat, seiring munculnya berbagai potensi usaha dari pembentukan wilayah ekowisata. Masyarakat diharapkan mendapat penghasilan dengan menyediakan jasa untuk kegiatan pengunjung, seperti menjadi pemandu wisata, menyediakan sarana menyelam, dan snorkeling (Jamaludin, 2015).

Tujuan dari adanya wisata snorkeling adalah agar para wisatawan dapat menikmati dan melihat keindahan bawah laut dari permukaan perairan dengan peralatan snorkeling serta dapat dilakukan tanpa adanya alat scuba (Johan $d k k$., 2011).

Lokasi yang dapat di jadikan sebagai kawasan ekowisata bahari kategori snorkeling harus memenuhi 7 parameter perairan yaitu kecerahan, tutupan karang, pertumbuhan karang /lifeform jenis ikan karang (spesies), kecepatan arus $\mathrm{cm} /$ detik), kedalaman dasar perairan $(\mathrm{m})$, lebar hamparan data karang (Yulianda, 2007). Di perairan Pulau Tikus pada ketiga stasiun tersebut masih belum memenuhi kriteria tersebut sehingga masih dikategorikan S3 ( sesuai bersyarat).

\section{Kesimpulan}

\section{KESIMPULAN DAN SARAN}

Tutupan ekosistem terumbu karang rata-rata di Pulau Tikus yaitu 37,59\% masuk kategori (sedang). Rata-rata kesesuaian ekowisata bahari kategori diving yaitu 60,4\% masuk dalam kategori S2 (sesuai) dan rata-rata kesesuaian ekowisata bahari kategori Snorkeling yaitu 46,33\% masuk dalam kategori S3 (sesuai bersyarat). 


\section{Saran}

Diharapkan adanya penelitian lebih lanjut tentang daya dukung kawasan di Pulau Tikus sehingga bisa memberikan informasi tentang pemanfaatan sumber daya alam yang ada dan jumlah maksimum pengunjung yang secara fisik dapat ditampung di kawasan yang disediakan pada waktu tertentu tanpa menimbulkan gangguan pada alam dan manusia. Dan di harapkan adanya study waktu melakukan diving dan snorkeling yang tepat, agar terhindar dari waktu arus dan ombak yang besar di Pulau Tikus.

\section{DAFTAR PUSTAKA}

Adi, A.B., A. Mustafa. dan R. Ketjulan. 2013. Kajian Potensi Kawasan dan Kesesuaian Ekowisata Terumbu Karang Pulau Laras Untuk Pengembagan Ekowisata Bahari. Jurnal Mina Laut Indonesia 1(1): (4960).

Arifin, T. D.G., Bengen dan J.J. Pariwono. 2002. Evaluasi Kesesuaian Kawasan Pesisir Teluk Palu Unutk Pengembangan Pariwisata Bahari. Jurnal Pesisir dan Laut 4(2):25-35.

Bakhtiar, D. dan Z. Ta'alidin, 2015. Kajian Identifikasi Terhadap Kondisi Pulau Tikus. Pemerintah Provinsi Bengkulu.

Bappeda Provinsi Bengkulu (2013). Bengkulu dalam angka Tahun 2013.http://www.bappeda.bengkuluprov.go.id. 2 Januari 2015.

English S., C. Wilkinson, dan U. Baker. 1997. Survey Manuals for Tropical Marine Resources. Australia Institute of Marine Science Townsville, Australian.

Jamaludin. 2015. Meluruskan Kembali Tujuan Ekowisata Bahari, Bekerja Lebih Giat Lagi. Universitas Jenderal Soedirman Purwokerto : artikel.

Johan, Y., F. Yulianda, V. P. Vincentius dan I. Karlina. 2011. Pengembangan Wisata Bahari dalam Pengelolaan Sumberdaya Pulau-Pulau Kecil Berbasis Kesesuaian dan Daya Dukung- Studi Kasus Pulau Sebesi Provinsi Lampung. Departemen Pengelolaan Pesisir dan laut Sekolah Pascasarjana IPB. Bogor.

Ketjulan, R. 2011. Daya dukung Perairan Pulau Hari sebagai Obyek Ekowisata Bahari. Jurnal Aqua Hayati, 7(3): 183-188.

Nybakken, J.W. 1992. Biologi Laut: Suatu Pendekatan Ekologis (Alih bahasa oleh: Muh. Eidman, Koesoebiono, Dietriech G.B., M. Hutomo, S. Sukardjo). Penerbit PT. Gramedia. Jakarta. 459 hal.

Yulianda, F., A. Fahridin., A.A. Hutabarat., S. Harteti., Kusharjani dan S.H. Kang, 2010. Pengelolaan pesisir dan laut secara terpadu. Cetakan ke dua. Departemen kehutanan RI secem- korea internasional cooperational cooperation agensy. Bogor 